\title{
Survey of factors affecting religious beliefs in physical education students
}

\author{
Mohammadbagher Forghani OZRUDI, Somayeh Rahimi ALIABADI \\ Teacher of Sama Elementary School, Sama Technical \& Vocational College,Islamic Azad University, Babol Branch, Babol, Iran. \\ Address Correspondance to M. Forghani Ozrudi,mb_forghani@yahoo.com
}

\begin{abstract}
This survey was performed in order to Factors affecting religious beliefs in physical education students with sub-purpose of the impact of family, university environment, instructors' educational method, university teachers' performance, and community. The survey method was a cross-sectional survey type, and the statistical population included all university teachers of Islamic Azad University, Sama unit, the number of which was 1316 people, and the statistical sample volume was 297 people which were determined based on various educational bases by stratified random sampling by using table of Morgan. The tool of survey was questionnaire depending on response surveyor made, based on Likert's design. Its validity and reliability was obtained $(\alpha=0.82)$ by using Cronbach Alpha test. The results showed that the impact of family, University environment, instructors' educational method, University teachers' performance, and community may greatly affect the internalization of religious values in students.
\end{abstract}

Keywords: Religious, physical education students, university environment, educational methods, teachers' performance.

\section{INTRODUCTION}

Education and training as an education center of children and adolescents and the most effective protector of cultural heritage has a high and lofty position among social institutions. The world whatever knows nowadays as behavioral and speech features of Iranian nation, and mentions it as the culture of Muslim nation of Iran is not firmed except in the home and school. The school and all those people who are working cultural and educational activities there have heavy responsibility as wide as thinking and cultural history of this nation. Nowadays, scholars and sociologists have acknowledged high importance of education than training, and believe that training without education is not only unconstructive, but it can also be destructive (13).

Nowadays, increase of global communications has caused many changes in the culture of various communities. Promotion of various thoughts, exposing to various thoughts and orientations are among threatening factors to dedication to identity of religious values especially among students $(2,5)$. Religion, in addition to the point that it is regarded as an important factor in social relations in respect of application, causes public encouraging, vitality, joy and passion. Moreover, in many times religion in sociological concept has mixed its external and objective dimensions with other national contents such as government, history, and cultural heritage (3).

Social psychologists have mentioned people's response to social influence (individual or group behavior being influenced by others) as follows: in making alike, a person considers another person as his/her model, and the action which he/she performs is not for acquiring reward or avoiding punishment, but it is performed in order to make him/herself alike that person; the meaning of internalization of an affair is that it becomes a part of personal conscience so that violating that value for a natural person provoke feelings of shame and wrongdoing, and the person has consciousness commitment to respect it (10). When ethical concepts are internalized, conditions are provided that people do not need lying and criminality and spontaneously emphasize on innate tendencies such as saving virtue, truth-seeking, and seeking perfection, and by changing time and place conditions, they are not changed (5).

Nasiri et al. (10) in a survey entitled as "Internalization of Islamic values among students 
from educational instructors' viewpoint have acknowledged that: 1 - there is relationship between educational methods of managers, assistants, educational instructors and internalizing Islamic values among students, 2- there is relationship between the content of educational lessons and internalizing Islamic values among students, 3- there is relationship between physical environment of school and internalizing Islamic values among students, 4- there is relationship between performing religious programs of schools and internalizing Islamic values among students (10).

Rezaie (11) in a survey entitled as "Investigating the ways of increasing youths' practical tendency towards religious problems from Islamic culture view" stated that: in this survey about the solutions of removing religion aversion and tendency towards alien culture, these points have been mentioned: introducing appropriate models, strengthening youths' religious insight and declaring western culture to them, eliminating economical poverty and providing useful and productive employment, preventing the influence of enemy's cultural factors, using physical training facilities" as ways to increase youths' scientific tendency towards religious issues (11).

The results of Karimi's (6) survey showed that there isn't difference between distribution of testing girls and boys in respect of considering and doing ethical values. Family and community have impact on internalizing values in girl and boy students having high and low self-esteem, and do not have impact among distribution of testing girls and boys in respect of getting impact from school and creating relationship with peers and their view towards themselves and their self-esteem (6).

Amadinejad\&Majidi (1) in a survey entitled as "Investigating Ways of Strengthening and Protecting Believing Religion and Religiosity of Young Generation against West Cultural Aggression" \&ShiriVasigh (4) in a survey entitled as "Investigating New Methods of Students' Physical Training from Viewpoint of Education and Training Scientists" \&Bigdeli (12) in a survey entitled as "Investigating the Reasons of Diminishing Ethical and Religious Issues among High School Students and the Role of Educational Instructors in Strengthening Religious Values" explained these results: 1- family has worthwhile role in religiosity and beliving religion, 2- family can make the youth resistant to cultural aggression by creating faith and believing in God, 3- by implementing tools such as sport and Quran and art centers in the schools and scientific centers, and training religion believing can be promoted and confront with western cultural aggression, and develop religion believing from young generation, 4- manager, employee, instructor, teacher, and even servant have educational role, all those people who are in the school according to their situation have impact, but the impact of school is not solely in this case, 5- school through educational program, textbook and their content can impact, and this is very important, 6- cultural behavior variables governing on schools, parents' attitude towards ethical and religious issues, social behaviors governing on schools, physical facilities of school, social behaviors governing on community, ethical and religious behaviors of professional teachers, ethical and behavioral features of teachers of Quran and religious insight, ethical and religious features of parents and ethical and religious behaviors of educational instructors have significant relationship with diminishing ethical and religious issues of students, 7- the behaviors governing on school and parents' attitude towards ethical and religious issues have had respectively the highest and the lowest impact on diminishing students' ethical and religious issues $(1,4,12)$.

It is clear that the type and method of ethical and educational training of students are factors which impact on their indifference towards religious values. Now, can educational instructors, teachers, the content of textbooks, and the atmosphere governing on the school reduce students' ethical deviations and lead them to religious values? Researcher worry of moral education and physical education students and given the fact that all the participants believed that the present generation is very different from previous generations, felt a deep generation gap and on the other hand some of the behaviors and movements and tendencies in the classroom, convince the researcher to respect the religious beliefs of students in physical education and problems affecting seriously to their studies and thus present research was provided. Undoubtedly these factors and factors outside school like family have high impact on this affair. Thus, the study is going to investigate: what factors have impact on internalizing religious values in students?

\section{MATERIAL \& METHOD}

Considering the major aims and questions developed in this study, the method of performing survey is field survey during which evaluation of effective factors which impact on internalizing 
religious values in students and its analysis has been carried out. The statistical population in this survey is all students of university of the Islamic Azad University, Sama unit in Babol city, that among them 297 students have been selected by using table of Morgan determining random sampling volume and implementing simple random sampling. In this containing 25 surveyor is on the basis of Likert fivevalues scales \& made questions was used that their face and content validity have been confirmed by experts and professionals and the test reliability has been obtained 0.82 by calculating Cronbach's alpha coefficient, and were provided to all sample people. Data analysis was performed using chi-square test. Accounting has been done by SPSS 22.0 software on level $p \leq 0.05$.

\section{RESULTS}

Result has shown $60.26 \%$ of tested are men $36.86 \%$ does have master degree and higher. Tested does have mean age of $36.42 \pm 7.38$ and past records about 13.21 \pm 7.97 . In order to investigate survey questions, in table $\chi^{2}$ offers calculations for evaluating difference significance. study in order to collect data, the questionnaire form

\section{DISCUSSION}

The results of the paper show that all the variables in the study of religious identity and positive relationship with youth. In other words, the increase in youth religious knowledge, religious identity is further strengthened youth. Based on the results obtained from survey findings, family, school environment, instructors' educational method, professional teachers' performance, and community in general have impact on internalizing values in students, and these findings are consistent with findings of Nasiri et al. (10), Rezaie (11), Amadinejad\&Majidi (1), Moradi (9), ShiriVasigh (4), Bigdeli (12). Introducing appropriate models, strengthening youths' religious insight and declaring western culture to them, eliminating economical poverty and providing useful and productive employment, preventing the influence of enemy's cultural factors, using physical training facilities have been stated as ways to increase youths' scientific tendency towards religious issues $(1,4,9-12)$.

Family change plays an important role in strengthening and weakening of religious beliefs, including religious students are

Table 1. Survey questions for evaluating difference significance.

\begin{tabular}{lllll}
\hline Survey Hypotheses & $\mathrm{n}$ & $\chi^{2}$ & $\mathrm{df}$ & $\mathrm{P}$ \\
\hline Family on internalizing religious values & 297 & 33.54 & 4 & 0.001 \\
School environment on internalizing religious values & 297 & 51.84 & 4 & 0.045 \\
Instructors' educational methods on internalizing religious values & 297 & 79.64 & 4 & 0.019 \\
Professional teachers on internalizing religious values & 297 & 45.46 & 4 & 0.006 \\
Community on internalizing religious values & 297 & 45.49 & 4 & 0.046 \\
\hline
\end{tabular}

Regarding the hypotheses related to internalizing religious values in students about the impact of family, since the computed square value is calculated $(x 2=33.54)$, thus $(P=0.001)$, about the impact of school environment, since the computed square value is calculated $(x 2=51.84)$, thus $(P=0.045)$, about the impact of instructors' educational methods, since the computed square value is calculated $(\times 2=79.64)$, thus $(\mathrm{P}=0.019)$, about the impact of elementary teachers' performance, since the computed square value is calculated $(x 2=45.46)$, thus $(\mathrm{P}=0.006)$, about the impact of community, since the computed square value is calculated $(\times 2=45.49)$, thus $(\mathrm{P}=0.046)$ with 4 freedom degree from $\times 2$ value of table which is greater than (9.45), therefore the mean of sample is significantly different from proposed value. claims of religion is not true youth and natural part of the difference is due to the age of the students concerned. Participate in religious circles and talking to family and use the TV in the religious beliefs of students and the number of the faithful to strengthen the use of satellites, foreign music and sleep and work without undermining the purpose of the students' religious beliefs. The problems show that the financial problems, unemployment, sexual, social decay, and worried about the future of the lack of resources and problems in the education of university physical education students is undermining religious beliefs.

The collective lives of humans in all communities are tied with values. If a community wants to be standing, certain values such as respect for others, observing commitments and truthfulness should exist in it. Thus, the collective life of human is important arena for forming values and 
internalizing them. On this basis, a group of ethical education methods supervise participation in social activities. In a semi-direct method, the teachers him/her self-inform people about particular social design and activity which has been designed previously. Special feature existing in this type of methods is that since action and activity is going in them, the decision making and selecting power grows in people. Acting and participating in activities is one of the most important ethical education methods and internalizing values; because by acting, our character is created. As Aristotle has said as builders become builder by building, humans become virtuous by doing virtues too (6).

\section{REFERENCES}

1. Ahmadinejad A, Majidi R. Investigating ways of strengthening and protecting believing religion and religiosity of young generation against west cultural aggression. Master Thesis, University of Hamedan, 2006; 3233

2. Amiri N, ReShadi M, Akhlaqipour M, AnbariRoozbahani M Factors influencing the formation of social identity Kermanshah University. University of Shoushtar Research Journal, 2014; 7(1): 197-216.

3. Bayat $Y$, Talkhani $M$. Investigating awareness ratio of girl and boy high school students in the province of Zanjan about religious orders. Researches of Education and Training of Zanjan Province, 2002; 42-45.

4. Bigdeli M. Investigating the reasons of diminishing ethical and religious issues among high school students and the role of educational instructors in strengthening religious values, and a survey project by using funds of ethical council of students in the Ardabil Province. Education and Training Researches in the Province of Ardabil, 2002; 52-59.
5. Emam Ali, Nahjolbalagha. Translated by Mohammad Dashti, Tehran, Faryan Press, 2015; 106-121.

6. Karimi A. Investigating the relationship between self-esteem and finding identity among 15- 18 years old adolescents in the city of Tehran. Master's Thesis, University of TarbiatMoalem. Tehran. 1996; 39-45.

7. Khedemi E. Effective Factors in Internalizing Islamic Values in Students. PhD. Thesis of Sociology, University of ShahidRajaie, 2010; 123-129.

8. Khosravi Z, Bagheri K. A guide for internalizing ethical values by lesson plan" Quarterly of Lesson Plan Studies, 2008; 2 (8): 81-105.

9. Moradi Z. Investigating the causes of youths' tendency towards religion in the city of Hamadan. Master Thesis, Field of Islamic Theology and Philosophy, Karaj, the Faculty of Islamic Theology and Philosophy, Islamic Azad University Karaj Unit, 2006; 31-33.

10. Nasiri F, Izadi S, Falahi AH, Shamkhani E. Internalizing Islamic values among students from educational instructors' viewpoint (Case study: Girl high schools of the city of Hamedan). Journal of Cultural Engineering, 2011; 6(5): 74-85.

11. Rezaie A. Investigating Ways of Increasing Youths' Practical Tendency Towards Religious Issues from Islamic Culture Perspective, Master Thesis, Field of Islamic Theology and Philosophy, Islamic Azad University, Arak Unit, 2008; 38-41.

12. ShiriVasigh A. Investigating New Methods of Students' Physical Training from Viewpoint of Education and Training Scientists, Research Project of Education and Training Organization of the Province of Hamedan, 2003; 44-47.

13. Zareshahabadi A, Ebrahimabadi M. Social factors related to the crisis of cultural identity among high school students in Tabriz. Journal of Cultural Research, 2012; 4(4): 207-228. 